Acta Crystallographica Section B

Structural

Science

ISSN 0108-7681

Andreas Lemmerer, ${ }^{*}$ Nikoletta B. Báthori and Susan A. Bourne*

Centre for Supramolecular Chemistry Research, Department of Chemistry, University of Cape

Town, Cape Town, South Africa

Correspondence e-mail:

andreas.lemmerer@gmail.com,

susan.bourne@uct.ac.za

\section{Chiral carboxylic acids and their effects on melting- point behaviour in co-crystals with isonicotinamide}

The crystal structures of co-crystals of two systems of chiral carboxylic acids, optically active and racemic 2-phenylpropionic acid and 2-phenylbutyric acid, with isonicotinamide are reported to investigate the effects of the chirality of the chiral carboxylic acids on the melting point of the co-crystal complexes. It was found that the racemic co-crystal has a higher melting point than the optically active co-crystal, which correlates with the denser packing arrangement inherent in centrosymmetric space groups.

\section{Introduction}

Control of the physical and chemical properties of co-crystals ${ }^{\mathbf{1}}$ (Aakeröy \& Salmon, 2005; Bond, 2007) is a goal in the crystal engineering field. The intention in bimolecular co-crystals is to control or improve a desired property of the components when compared with their unimolecular state. In pharmaceutical co-crystals (Vishweshwar et al., 2006; Childs \& Hardcastle, 2007), for example, this would be an improvement of the bioavailability of an active pharmaceutical ingredient, compared with its pure form, by co-crystallizing it with a suitably safe molecule, called the co-crystal former (Remenar et al., 2003). The stability of the drugs is also desired in promoting shelf-life, for example against hydration (Friščić et al., 2008). Chiral compounds have been shown to differ in their thermodynamic properties depending on whether they are present as the enantiomer or the racemate. An empirically deduced rule (Wallach's rule) states that the racemate has a more dense crystal structure than the enantiomer. However, this rule, which was based on only eight pairs of racemic and optically active compounds and their densities, has been reevaluated by Brock et al. (1991) by investigating 129 pairs of racemic and chiral crystals located in the Cambridge Structural Database. Although the observation appears to be the case in the majority of compounds, Brock et al. (1991) attributed this tendency of the racemate to be more stable (and denser) than their chiral counterparts to be due to 'favourable packing arrangements in racemic space groups compared with chiral ones' and not a 'consequence of any special kinds of interactions between opposite enantiomers'. Chiral carboxylic acids generally also have the racemate melting at a higher temperature than the enantiomer, although exceptions exist (Gabard \& Collett, 1986; Larsen \& Marthi, 1994, 1995, 1997; Marthi et al., 1994; Sørensen \& Larsen, 2003; Riis \& Larsen, 2005). The different melting behaviour of chiral carboxylic acids and its effects on cocrystal stability has been observed by Friščić \& Jones (2007)

\footnotetext{
${ }^{1}$ In this study the term co-crystals is used as a synonym for multi-component molecular crystal and includes crystal structures made up of molecules that are in different physical states at room temperature.
}

Received 11 August 2008

Accepted 22 October 2008

Dedicated to Professor F. R. L. Schöning on the occasion of his 85 th birthday.
(C) 2008 International Union of Crystallography Printed in Singapore - all rights reserved 
when preparing co-crystals of nicotinamide (Vitamin $\mathrm{B}_{3}$ ) with optically active and racemic forms of ibuprofen and mandelic acid. (RS)-Ibuprofen melts at $349 \mathrm{~K}$ and $(S)$-ibuprofen at $323 \mathrm{~K}$, thus obeying Wallach's rule. Co-crystals with nicotinamide indeed follow the same trend, with the racemic cocrystal melting $9 \mathrm{~K}$ higher than the optically active co-crystal. The thermal behaviour of $(R S)$-mandelic acid, melting at $390 \mathrm{~K}$, compared with $(R)$ - or $(S)$-mandelic $(403 \mathrm{~K})$ goes against Wallach's rule and this continues to its co-crystal

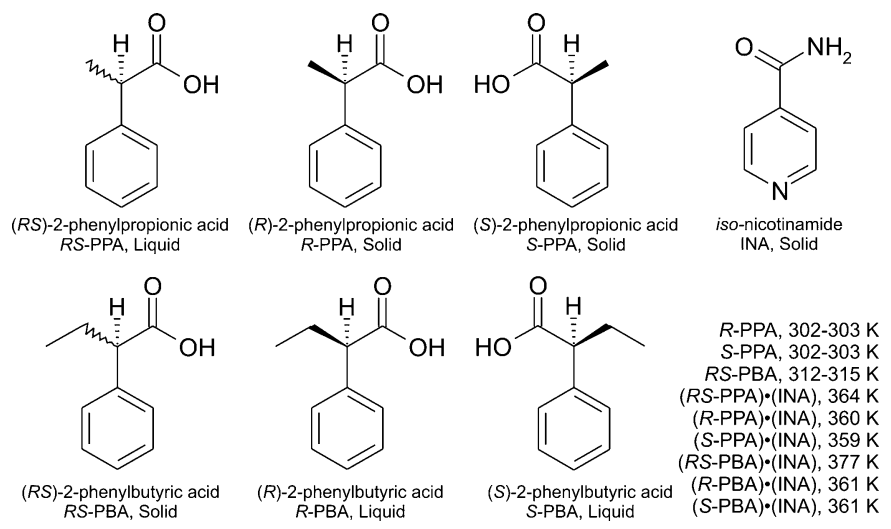

Figure 1

The chiral molecules (PPA and PBA) used in this study to make cocrystals with isonicotinamide (INA). The physical states at room temperature and relevant melting points of the compounds are given.

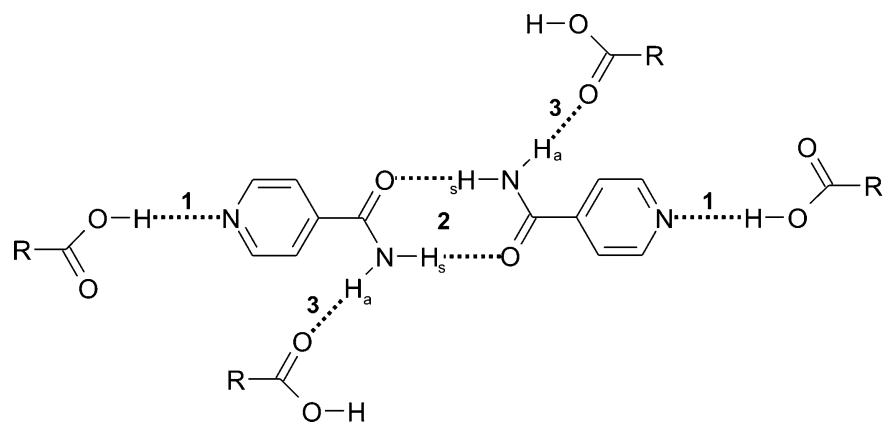

Figure 2

The carboxylic acid $\cdots$ pyridine [synthon (1)], carboxamide dimer [synthon (2)] and amide...carbonyl [synthon (3)] hydrogen-bonding interactions observed in this study. formation with nicotinamide, which has the same relative difference in melting point ( 362 versus $349 \mathrm{~K}$ ).

To delve further into this matter and continue the work set out by Friščić \& Jones (2007), we chose two sets of chiral carboxylic acids as co-crystal formers. 2-Phenylpropionic acid (PPA) is readily available from Aldrich as both the racemate (RS-PPA) and optically active forms ( $R$-PPA and $S$-PPA). 2Phenylpropionic acid is structurally related to ibuprofen, missing the tertiary butyl group para to the propionic acid chain. Interestingly, 2-phenylpropionic acid does not follow Wallach's rule. $R S$-PPA is a liquid at room temperature and $R$ PPA or $S$-PPA acid is a solid, melting at $302-303 \mathrm{~K}$ (Fig. 1). The second chiral carboxylic acid is 2-phenylbutyric acid (PBA), which has an extra methyl group. Here Wallach's rule is obeyed, with the racemate ( $R S$-PBA) a solid at room temperature and the two optically active forms liquids $(R$ PBA and $S$-PBA).

The second component of the co-crystals is isonicotinamide (INA). Carboxylic acids and isonicotinamide undergo a supramolecular reaction to form a supermolecule (Aakeröy et al., 2002). This supramolecular reaction has yielded predictable structures based on the robustness of the two supramolecular synthons involved (Fig. 2). Synthon (1) is a heteromeric carboxylic acid...pyridine hydrogen bond and synthon (2) is a homomeric amide - . amide dimer through the $\mathrm{H}$ atom in the syn position. The combination of the two synthons forms a four-membered 'supermolecule'. Individual supermolecules are connected through the anti $\mathrm{H}$ of the amide [synthon (3)] to form higher dimensional supramolecular structures, referred to as supramolecular isomerism (Moulton \& Zaworotko, 2001). Aakeröy et al. (2002) identified two such isomers, one forming infinite one-dimensional ribbons and the other forming a cross-linked two-dimensional network. The former isomer crystallizes in $P \overline{1}$ and the latter in $C 2 / c$. Within the four-membered supermolecule, the four carbonyl moieties can be either trans-trans-trans [(I) conformation] or cis-transcis [(II) conformation; Aakeröy et al., 2002]. See Figs. 3 and 4.

\section{Experimental}

\subsection{Crystal growth}

All reagents and solvents were obtained from Aldrich and used without further purification.

2.1.1. Preparation of $(R)-2$ phenylpropionic acid, (S)-2phenylpropionic acid and (RS)-2phenylbutyric acid. Diffractionquality single crystals of enantiopure $(R)$-2-phenylpropionic acid and (S)-2-phenylpropionic acid, and racemic $(R S)$-2-phenylbutyric acid were found in commercial containers.

2.1.2. Preparation of (RS)-2phenylpropionic acid.isonicotinamide. Co-crystals were prepared

Figure 3

The asymmetric unit and atomic-numbering scheme of the three chiral carboxylic acids that are solids at room temperature. The anisotropic displacement parameters are shown at the $50 \%$ probability level. 


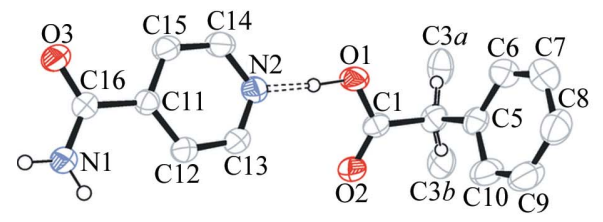

(RS-PPA)•(INA)

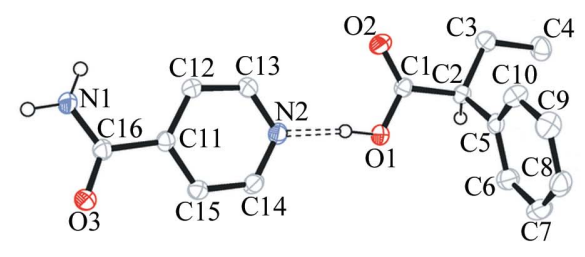

(RS-PBA)•(INA)

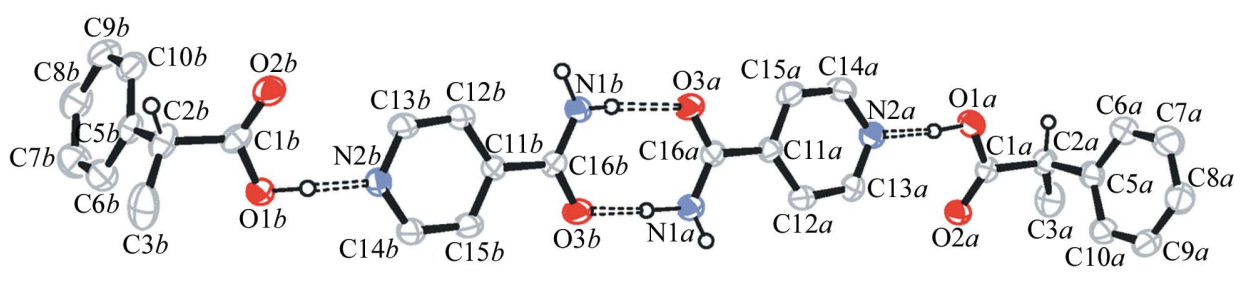

(R-PPA)・(INA)
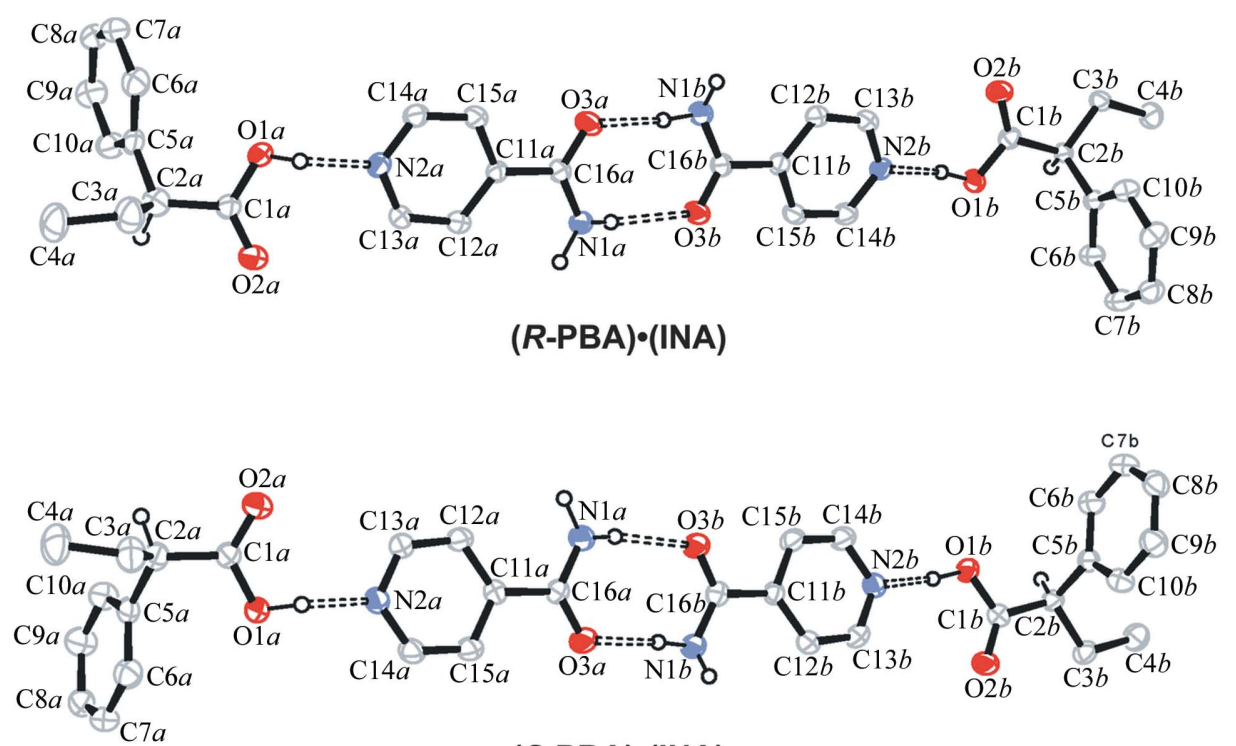

(S-PBA)•(INA)

2.1.4. Preparation of (S)-2phenylpropionic acid.isonicotinamide. Co-crystals were prepared by dissolving $0.100 \mathrm{~g}$ of isonicotinamide $(0.793 \mathrm{mmol})$ and $0.112 \mathrm{~g}$ of $(S)$-2-phenylpropionic acid $(0.793 \mathrm{mmol})$ in $3 \mathrm{ml}$ of acetonitrile. Slow evaporation resulted in small crystals (microcrystalline powder) suitable for Xray powder diffraction. Growth of single-crystal $\mathrm{X}$-diffraction quality crystals from other solvents such as methanol, ethanol, $n$-butanol and 2-butanone were not successful. ${ }^{2}$ Elemental analysis (\%): calc. for $\mathrm{C}_{15} \mathrm{H}_{16} \mathrm{~N}_{2} \mathrm{O}_{3}$ : C 66.16, H 5.92, N 10.29; found: C $66.20, \mathrm{H} 6.00, \mathrm{~N}$ 10.26 .

2.1.5. Preparation of (RS)-2phenylbutyric acid.isonicotinamide. Co-crystals were prepared by dissolving $0.100 \mathrm{~g}$ of isonicotinamide $(0.793 \mathrm{mmol})$ and $0.130 \mathrm{~g}$ of $(R S)$-2-phenylbutyric acid $(0.793 \mathrm{mmol})$ in $5 \mathrm{ml}$ of a $50 /$ $50 \quad(\mathrm{v} / \mathrm{v})$ methanol/2-butanone solution. Crystals were grown by slow evaporation. Elemental analysis (\%): calc. for $\mathrm{C}_{16} \mathrm{H}_{18}$ $\mathrm{N}_{2} \mathrm{O}_{3}$ : C 67.12, H 6.34, N 9.78; found: $\mathrm{C} 67.00, \mathrm{H} 6.37, \mathrm{~N}$ 9.68 .

2.1.6. Preparation of $(R)-2-$ phenylbutyric acid.isonicotinamide. Co-crystals were prepared by dissolving $0.100 \mathrm{~g}$ of isonicotinamide $(0.793 \mathrm{mmol})$ and $0.130 \mathrm{~g}$ of $(R)$-2-phenylbutyric acid $(0.793 \mathrm{mmol})$ in $1 \mathrm{ml}$ of acetonitrile. After evaporation of the solvent, a gel-like amorphous mass formed. Single crystals were

by dissolving $0.100 \mathrm{~g}$ of isonicotinamide $(0.793 \mathrm{mmol})$ and $0.112 \mathrm{~g}$ of $(R S)$-2-phenylpropionic acid $(0.793 \mathrm{mmol})$ in $5 \mathrm{ml}$ of $50 / 50(\mathrm{v} / \mathrm{v})$ methanol/2-butanone. Crystals were grown by slow evaporation. Elemental analysis (\%): calc. for $\mathrm{C}_{15} \mathrm{H}_{16} \mathrm{~N}_{2} \mathrm{O}_{3}$ : C 66.16, H 5.92, N 10.29; found: C 66.03, H 5.93, $\mathrm{N} 10.46$.

2.1.3. Preparation of $(R)$-2-phenylpropionic acidisonicotinamide. Co-crystals were prepared by dissolving $0.100 \mathrm{~g}$ of isonicotinamide $(0.793 \mathrm{mmol})$ and $0.112 \mathrm{~g}$ of $(R)-2-$ phenylpropionic acid $(0.793 \mathrm{mmol})$ in $3 \mathrm{ml}$ of acetonitrile. Crystals were grown by slow evaporation. Elemental analysis (\%): calc. for $\mathrm{C}_{15} \mathrm{H}_{16} \mathrm{~N}_{2} \mathrm{O}_{3}$ : C 66.16, H 5.92, N 10.29; found: $\mathrm{C}$ 66.13, H 5.90, N 10.27. grown subsequently using seed crystals taken from the racemate co-crystal. Elemental analysis (\%): calc. for $\mathrm{C}_{16} \mathrm{H}_{18}$ $\mathrm{N}_{2} \mathrm{O}_{3}$ : C 67.12, H 6.34, N 9.78; found: C 67.08, H 6.30, N 9.50 .

2.1.7. Preparation of (S)-2-phenylbutyric acidisonicotinamide. The same procedure was used as for $(R)$ 2-phenylbutyric acid.isonicotinamide. Elemental analysis (\%): calc. for $\mathrm{C}_{16} \mathrm{H}_{18} \mathrm{~N}_{2} \mathrm{O}_{3}: \mathrm{C} 67.12, \mathrm{H}$ 6.34, N 9.78; found: C 67.13, H 6.31, N 9.70.

\footnotetext{
${ }^{2}$ A unit-cell similar to that of (R-PPA).(INA) was indexed on a small crystal but was not of sufficient quality for data collection.
} 
Table 1

Crystal data for chiral carboxylic acids.

\begin{tabular}{|c|c|c|c|}
\hline Compound & $R$-PPA & $S$-PPA & $R S$-PBA \\
\hline \multicolumn{4}{|l|}{ Crystal data } \\
\hline Chemical formula & $\mathrm{C}_{9} \mathrm{H}_{10} \mathrm{O}_{2}$ & $\mathrm{C}_{9} \mathrm{H}_{10} \mathrm{O}_{2}$ & $\mathrm{C}_{10} \mathrm{H}_{12} \mathrm{O}_{2}$ \\
\hline$M_{r}$ & 150.17 & 150.17 & 164.2 \\
\hline Cell setting, space group & Monoclinic, $P 2_{1}$ & Monoclinic, $P 2_{1}$ & Orthorhombic, $\mathrm{Pbca}$ \\
\hline Temperature (K) & $173(2)$ & $173(2)$ & $173(2)$ \\
\hline$a, b, c(\AA)$ & $6.3758(13), 7.1703(14), 8.6281$ (17) & $6.4280(13), 7.1935(14), 8.6507(17)$ & $9.1724(18), 7.1850(14), 27.407$ (6) \\
\hline$\beta\left(^{\circ}\right)$ & $100.64(3)$ & $100.41(3)$ & $90,90,90$ \\
\hline$V\left(\AA^{3}\right)$ & $387.66(13)$ & $393.43(13)$ & $1806.2(6)$ \\
\hline$Z$ & 2 & 2 & 8 \\
\hline$D_{x}\left(\mathrm{Mg} \mathrm{m}^{-3}\right)$ & 1.286 & 1.268 & 1.208 \\
\hline Radiation type & Mo $K \alpha$ & Mo $K \alpha$ & Mo $K \alpha$ \\
\hline$\mu\left(\mathrm{mm}^{-1}\right)$ & 0.09 & 0.09 & 0.08 \\
\hline Crystal form, colour & Spheroid, colourless & Spheroid, colourless & Block, colourless \\
\hline Crystal size (mm) & $0.55 \times 0.46 \times 0.4$ & $0.45 \times 0.4 \times 0.38$ & $0.4 \times 0.32 \times 0.2$ \\
\hline \multicolumn{4}{|l|}{ Data collection } \\
\hline Diffractometer & Nonius KappaCCD area-detector & Nonius KappaCCD area-detector & Nonius KappaCCD area-detector \\
\hline Data collection method & $2.0^{\circ} \varphi$ and $\omega$ scans & $2.0^{\circ} \varphi$ and $\omega$ scans & $0.9^{\circ} \varphi$ and $\omega$ scans \\
\hline Absorption correction & Multi-scan $\dagger$ & Multi-scan $\dagger$ & Multi-scan $\dagger$ \\
\hline$T_{\min }$ & 0.953 & 0.963 & 0.968 \\
\hline$T_{\max }$ & 0.967 & 0.970 & 0.984 \\
\hline $\begin{array}{l}\text { No. of measured, independent and } \\
\text { observed reflections }\end{array}$ & $6058,1001,910$ & $4966,801,676$ & $9148,1669,1329$ \\
\hline Criterion for observed reflections & $I>2 \sigma(I)$ & $I>2 \sigma(I)$ & $I>2 \sigma(I)$ \\
\hline$R_{\text {int }}$ & 0.029 & 0.042 & 0.033 \\
\hline$\theta_{\max }\left({ }^{\circ}\right)$ & 28.0 & 25.5 & 25.5 \\
\hline \multicolumn{4}{|l|}{ Refinement } \\
\hline Refinement on & $F^{2}$ & $F^{2}$ & $F^{2}$ \\
\hline$R\left[F^{2}>2 \sigma\left(F^{2}\right)\right], w R\left(F^{2}\right), S$ & $0.034,0.090,0.98$ & $0.040,0.1,1.07$ & $0.037,0.088,1.04$ \\
\hline No. of reflections & 1001 & 801 & 1669 \\
\hline No. of parameters & 104 & 104 & 114 \\
\hline H-atom treatment & Mixture $\ddagger$ & Mixture $\ddagger$ & Mixture $\ddagger$ \\
\hline Weighting scheme & $\begin{array}{l}w=1 /\left[\sigma^{2}\left(F_{o}^{2}\right)+(0.0628 P)^{2}+0.0427 P\right] \\
\quad \text { where } P=\left(F_{o}^{2}+2 F_{c}^{2}\right) / 3\end{array}$ & $\begin{array}{l}w=1 /\left[\sigma^{2}\left(F_{o}^{2}\right)+(0.0613 P)^{2}+0.0318 P\right] \\
\quad \text { where } P=\left(F_{o}^{2}+2 F_{c}^{2}\right) / 3\end{array}$ & $\begin{array}{l}w=1 /\left[\sigma^{2}\left(F_{o}^{2}\right)+(0.0324 P)^{2}+0.4861 P\right] \\
\quad \text { where } P=\left(F_{o}^{2}+2 F_{c}^{2}\right) / 3\end{array}$ \\
\hline$(\Delta / \sigma)_{\max }$ & 0.035 & 0.004 & 0.001 \\
\hline$\Delta \rho_{\max }, \Delta \rho_{\min }\left(\mathrm{e} \AA^{-3}\right)$ & $0.13,-0.19$ & $0.17,-0.19$ & $0.16,-0.14$ \\
\hline
\end{tabular}

$\dagger$ Based on symmetry-related measurements. $\quad$ \$ Mixture of independent and constrained refinement.

\subsection{Differential scanning calorimetry (DSC) measurements}

Differential scanning calorimetry was performed using a Perkin Elmer DSC7, heating rate $10 \mathrm{~K} \mathrm{~min}^{-1}$, under an atmosphere of dry $\mathrm{N}_{2}$ flowing at $40 \mathrm{~cm}^{3} \mathrm{~min}^{-1}$. See supplementary information ${ }^{3}$ for DSC traces of all co-crystal compounds.

\subsection{Single-crystal X-ray crystallography (SCXRD)}

All data for crystal and molecular structure determination, except for ( $S$-PPA).(INA), were measured on a Nonius KappaCCD diffractometer using graphite-monochromated Mo $K \alpha$ radiation $(0.7107 \AA)$ at $173 \mathrm{~K}$ using COLLECT (Nonius, 1998). The unit cell was indexed from the first 20 frames and positional data were refined along with diffractometer constants to give the final cell parameters ( $S C A L E$ $S C A L E P A C K$; Otowinski \& Minor, 1997). Integration and

\footnotetext{
${ }^{3}$ Supplementary data for this paper are available from the IUCr electronic archives (Reference: BS5070). Services for accessing these data are described at the back of the journal.
}

scaling correction performed using SCALEPACK and $D E N Z O$ (Otowinski \& Minor, 1997) resulted in unique datasets corrected for Lorentz polarization effects. Semiempirical absorption corrections were performed using the program $S A D A B S$ (Bruker AXS Inc., 2004) on compounds $R$ PPA, $S$-PPA and $R S$-PBA; and face-indexed absorption corrections were performed using the program XPREP (Bruker AXS Inc., 2004) on the co-crystal compounds. The structures were solved using SHELXS97 (Sheldrick, 2008) and refined using the full-matrix least-squares methods in SHELXL97 (Sheldrick, 2008) with the aid of the program WinGX (Farrugia, 1999). Non-H atoms were modeled anisotropically. $\mathrm{H}$ atoms on $\mathrm{C}$ atoms were assigned an isotropic displacement parameter 1.2 or 1.5 times that of their parent atom and refined using a riding model. $\mathrm{H}$ atoms on the amine and carboxylic acid were located from the difference-Fourier map and their positional parameters refined freely, however, with an isotropic displacement parameter 1.2 times that of the parent $\mathrm{N}$ or $\mathrm{O}$ atom. Experimental details of the $\mathrm{X}$-ray analyses are provided in Table 1. Diagrams and publication 
Table 2

Crystal data for co-crystals [except for $(S$-PPA) (INA)].

\begin{tabular}{|c|c|c|c|c|c|}
\hline Compound & $(R S$-PPA $) \cdot($ INA $)$ & $(R$-PPA $) \cdot($ INA $)$ & $(R S$-PBA $) \cdot($ INA $)$ & $(R-\mathrm{PBA}) \cdot(\mathrm{INA})$ & $(S$-PBA $) \cdot($ INA $)$ \\
\hline \multicolumn{6}{|l|}{ Crystal data } \\
\hline Chemical formula & $\mathrm{C}_{9} \mathrm{H}_{10} \mathrm{O}_{2} \cdot \mathrm{C}_{6} \mathrm{H}_{6} \mathrm{~N}_{2} \mathrm{O}$ & $\mathrm{C}_{9} \mathrm{H}_{10} \mathrm{O}_{2} \cdot \mathrm{C}_{6} \mathrm{H}_{6} \mathrm{~N}_{2} \mathrm{O}$ & $\mathrm{C}_{10} \mathrm{H}_{12} \mathrm{O}_{2} \cdot \mathrm{C}_{6} \mathrm{H}_{6} \mathrm{~N}_{2} \mathrm{O}$ & $\mathrm{C}_{10} \mathrm{H}_{12} \mathrm{O}_{2} \cdot \mathrm{C}_{6} \mathrm{H}_{6} \mathrm{~N}_{2} \mathrm{O}$ & $\mathrm{C}_{10} \mathrm{H}_{12} \mathrm{O}_{2} \cdot \mathrm{C}_{6} \mathrm{H}_{6} \mathrm{~N}_{2} \mathrm{O}$ \\
\hline$M_{r}$ & 272.3 & 272.3 & 286.32 & 286.32 & 286.32 \\
\hline Cell setting, space group & Monoclinic, $C 2 / c$ & Monoclinic, $C 2$ & Triclinic, $P \overline{1}$ & Triclinic, $P 1$ & Triclinic, $P 1$ \\
\hline Temperature (K) & $173(2)$ & $173(2)$ & $173(2)$ & $173(2)$ & $173(2)$ \\
\hline$a, b, c(\AA)$ & $\begin{array}{l}31.899(3), 5.4007(5) \\
20.8815(16)\end{array}$ & $\begin{array}{l}32.006(2), 5.4698(4), \\
20.8451(10)\end{array}$ & $\begin{array}{l}5.7543(5), 9.6867(8), \\
13.7434(12)\end{array}$ & $\begin{array}{l}5.6984(4), 9.7762(10) \\
13.8553(13)\end{array}$ & $\begin{array}{l}5.7059(3), 9.7727(4) \\
13.8321(7)\end{array}$ \\
\hline$\alpha, \beta, \gamma\left({ }^{\circ}\right)$ & $90,128.319(3), 90$ & $128.690(3)$ & $\begin{array}{l}102.056(5), 93.206(4) \\
103.524(5)\end{array}$ & $\begin{array}{c}100.011(3), 94.302(5) \\
103.919(5)\end{array}$ & $\begin{array}{c}100.323(3), 94.090(2) \\
103.881(3)\end{array}$ \\
\hline$V\left(\AA^{3}\right)$ & $2822.4(4)$ & $2848.4(3)$ & $723.95(11)$ & $732.26(11)$ & $731.36(6)$ \\
\hline$Z$ & 8 & 8 & 2 & 2 & 2 \\
\hline$D_{x}\left(\mathrm{Mg} \mathrm{m}^{-3}\right)$ & 1.282 & 1.27 & 1.313 & 1.299 & 1.3 \\
\hline Radiation type & Mo $K \alpha$ & Mo $K \alpha$ & Mo $K \alpha$ & Mo $K \alpha$ & Mo $K \alpha$ \\
\hline$\mu\left(\mathrm{mm}^{-1}\right)$ & 0.09 & 0.09 & 0.09 & 0.09 & 0.09 \\
\hline Crystal form, colour & Block, colourless & Plate, colourless & Block, colourless & Plate, colourless & Block, colourless \\
\hline Crystal size (mm) & $0.49 \times 0.08 \times 0.06$ & $0.38 \times 0.15 \times 0.03$ & $0.4 \times 0.16 \times 0.13$ & $0.21 \times 0.09 \times 0.03$ & $0.47 \times 0.2 \times 0.09$ \\
\hline \multicolumn{6}{|l|}{ Data collection } \\
\hline Diffractometer & $\begin{array}{l}\text { Nonius KappaCCD area- } \\
\text { detector }\end{array}$ & $\begin{array}{l}\text { Nonius KappaCCD area- } \\
\text { detector }\end{array}$ & $\begin{array}{l}\text { Nonius KappaCCD area- } \\
\text { detector }\end{array}$ & $\begin{array}{l}\text { Nonius KappaCCD area- } \\
\text { detector }\end{array}$ & $\begin{array}{l}\text { Nonius KappaCCD area- } \\
\text { detector }\end{array}$ \\
\hline Data collection method & $1.5^{\circ} \varphi$ and $\omega$ scans & $2.0^{\circ} \varphi$ and $\omega$ scans & $2.0^{\circ} \varphi$ and $\omega$ scans & $2.0^{\circ} \varphi$ and $\omega$ scans & $2.0^{\circ} \varphi$ and $\omega$ scans \\
\hline Absorption correction & Integration & Integration & Integration & Integration & Integration \\
\hline$T_{\min }$ & 0.961 & 0.973 & 0.970 & 0.983 & 0.953 \\
\hline$T_{\max }$ & 0.994 & 0.997 & 0.994 & 0.997 & 0.992 \\
\hline $\begin{array}{l}\text { No. of measured, inde- } \\
\text { pendent and observed } \\
\text { reflections }\end{array}$ & $19532,3204,1930$ & $21632,3784,2254$ & $12417,3488,2674$ & $18175,3541,2350$ & $18714,3529,3151$ \\
\hline $\begin{array}{l}\text { Criterion for observed } \\
\text { reflections }\end{array}$ & $I>2 \sigma(I)$ & $I>2 \sigma(I)$ & $I>2 \sigma(I)$ & $I>2 \sigma(I)$ & $I>2 \sigma(I)$ \\
\hline$R_{\text {int }}$ & 0.074 & 0.072 & 0.061 & 0.073 & 0.068 \\
\hline$\theta_{\max }\left({ }^{\circ}\right)$ & 27.5 & 28.0 & 28.0 & 28 & 28 \\
\hline \multicolumn{6}{|l|}{ Refinement } \\
\hline Refinement on & $F^{2}$ & $F^{2}$ & $F^{2}$ & $F^{2}$ & $F^{2}$ \\
\hline$R\left[F^{2}>2 \sigma\left(F^{2}\right)\right], w R\left(F^{2}\right), S$ & $0.055,0.155,1.04$ & $0.049,0.123,1.04$ & $0.045,0.123,1.05$ & $0.047,0.109,1.01$ & $0.053,0.151,1.04$ \\
\hline No. of reflections & 3204 & 3784 & 3488 & 3541 & 3529 \\
\hline No. of parameters & 202 & 380 & 200 & 399 & 399 \\
\hline $\mathrm{H}$-atom treatment & Mixture $\dagger$ & Mixture $\dagger$ & Mixture $\dagger$ & Mixture $\dagger$ & Mixture $\dagger$ \\
\hline Weighting scheme & $\begin{array}{l}w=1 /\left[\sigma^{2}\left(F_{o}^{2}\right)+\right. \\
\left.\quad(0.0857 P)^{2}\right], \text { where } P= \\
\quad\left(F_{o}^{2}+2 F_{c}^{2}\right) / 3\end{array}$ & $\begin{array}{l}w=1 /\left[\sigma^{2}\left(F_{o}^{2}\right)+\right. \\
\left.\quad(0.0587 P)^{2}+0.0245 P\right], \\
\quad \text { where } P=\left(F_{o}^{2}+2 F_{c}^{2}\right) / 3\end{array}$ & $\begin{array}{l}w=1 /\left[\sigma^{2}\left(F_{o}^{2}\right)+\right. \\
\left.\quad(0.0588 P)^{2}+0.1607 P\right], \\
\quad \text { where } P=\left(F_{o}^{2}+2 F_{c}^{2}\right) / 3\end{array}$ & $\begin{array}{l}w=1 /\left[\sigma^{2}\left(F_{o}^{2}\right)+\right. \\
\left.\quad(0.057 P)^{2}\right], \text { where } P= \\
\quad\left(F_{o}^{2}+2 F_{c}^{2}\right) / 3\end{array}$ & $\begin{array}{l}w=1 /\left[\sigma^{2}\left(F_{o}^{2}\right)+\right. \\
\left.\quad(0.1071 P)^{2}+0.108 P\right] \\
\quad \text { where } P=\left(F_{o}^{2}+2 F_{c}^{2}\right) / 3\end{array}$ \\
\hline$(\Delta / \sigma)_{\max }$ & $0.001^{\circ}$ & 0.001 & $<0.0001$ & 0.001 & $<0.0001$ \\
\hline$\Delta \rho_{\max }, \Delta \rho_{\min }\left(\mathrm{e} \AA^{-3}\right)$ & $0.30,-0.24$ & $0.20,-0.28$ & $0.31,-0.21$ & $0.18,-0.22$ & $0.78,-0.27$ \\
\hline
\end{tabular}

$\dagger$ Mixture of independent and constrained refinement.

material were generated using ORTEP3 (Farrugia, 1997), PLATON (Spek, 2003), DIAMOND (Brandenburg, 1999) and Win $G X$ (Farrugia, 1999).

\subsection{Powder X-ray diffraction (PXRD)}

X-ray powder diffraction (HUBER Guinier 670 Imaging Plate diffractometer with $\mathrm{Cu} K \alpha_{1}$ radiation, $1.5405981 \AA$ ) at $T=293 \mathrm{~K}$ established that the bulk material had the same crystal structure as the crystals selected for single-crystal analysis. The peak positions are shifted owing to the different temperatures at which the measured sample was carried out compared with the calculated pattern. The peak intensities vary, perhaps due to microcrystalline orientation and/or texture effects. See the supplementary material for PXRD patterns of all co-crystals.

\section{Results and discussion}

\subsection{Crystal structures of the chiral carboxylic acids}

The X-ray crystal structures of the chiral carboxylic acids which are solid at room temperature have been determined to attempt to explain the different melting-point behaviour in the 2-phenylpropionic acids and 2-phenylbutyric acids. The compound $R$-PPA, melting at 302-303 K (Beilstein 9, IV, 1779) has the carboxylic acid proton in the syn conformation and the syn,syn-catemer motif is formed through $\mathrm{O} 1-\mathrm{H} 1 \cdots \mathrm{O} 2$ hydrogen bonds (Table 2). The catemer extends along the direction of the $b$ axis and molecules are related by the twofold screw axis in $P 2_{1}$. Catemer formation is supported by a $\mathrm{C}-\mathrm{H} \cdots \mathrm{O}$ hydrogen bond from the methine hydrogen to the carboxylate oxygen (Desiraju, 2005). Adjacent catemers are linked via $\mathrm{C} 9-\mathrm{H} 9 \cdots \pi$ hydrogen bonds $\left[\begin{array}{ll}d & 2.84 \AA\end{array}\right.$ 3.589 (2) $\AA, \theta=137^{\circ}$ ] along the $c$ axis and along the $b$ axis by 
C6-H6 $\cdots \pi$ hydrogen bonds $[d=2.82 \AA, D=3.572(2) \AA, \theta=$ $137^{\circ}$. The crystal structure of $S$-PPA is enantiomorphic to $R$ PPA and not described further. The crystal packing of the racemic $R S$-PPA cannot be determined as it is in the liquid phase.

In the 2-phenylbutyric acids, the reverse scenario is encountered. The racemic $R S$-PBA is a solid at room temperature, melting at 312-315 K (Beilstein 9, IV, 1815). The racemic molecules form centrosymmetric dimers that pack in a herringbone fashion along the $c$ axis (Fig. $5 b$ ). The $\mathrm{O}-\mathrm{H} \cdots \mathrm{O}$ hydrogen bond is $1.67(2) \AA$ and fairly linear $\left[172(2)^{\circ}\right]$. The

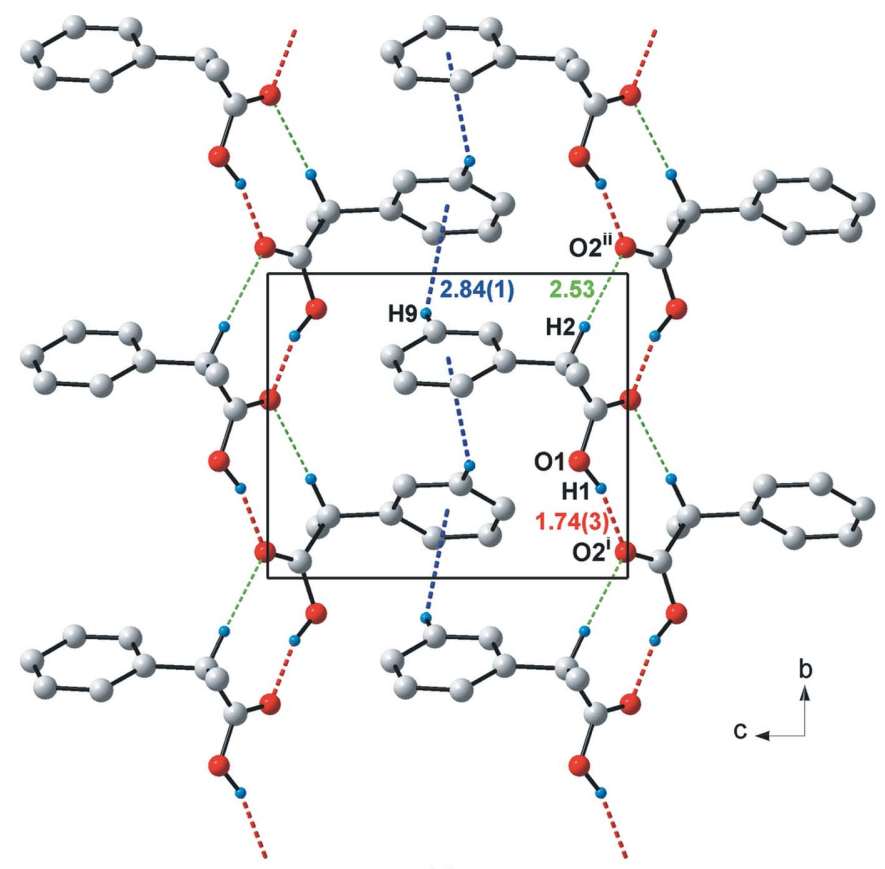

(a)

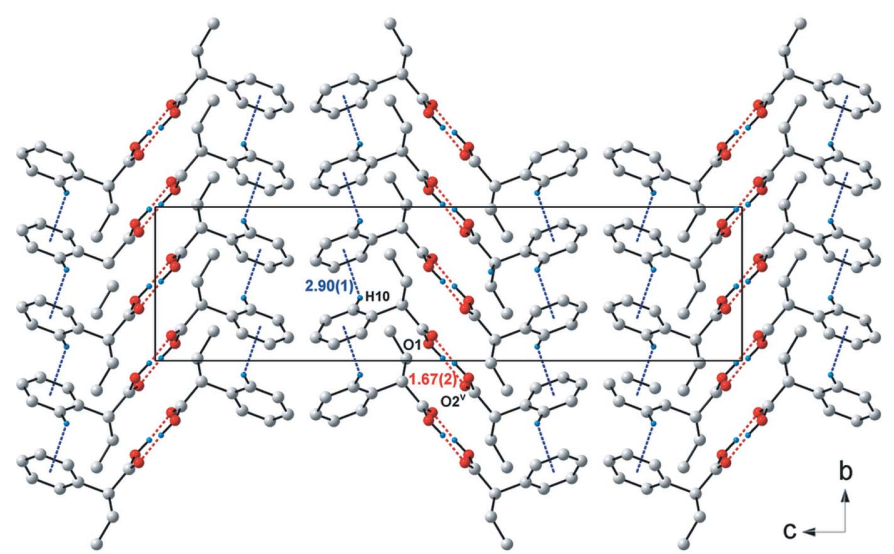

(b)

Figure 5

Packing diagrams of the chiral carboxylic acids used in this study. (a) The syn,syn catemeric chain of $R$-PPA formed by the $\mathrm{O}-\mathrm{H} \cdots \mathrm{O}$ hydrogen bonds (red lines), the supporting $\mathrm{C}-\mathrm{H} \cdots \mathrm{O}$ hydrogen bond (green lines) and the $\mathrm{C}-\mathrm{H} \cdots \pi$ hydrogen bonds (blue lines) connecting adjacent chains. (b) The hydrogen-bonded dimers of $R S$-PBA, which pack in a herringbone fashion. $\mathrm{H}$ atoms not involved in hydrogen bonding are omitted for clarity. Symmetry codes: (i) $-x+1, y-\frac{1}{2},-z$; (ii) $-x+1, y+\frac{1}{2},-z ;(\mathrm{v})-x+1,-y,-z+1$. dimers pack in a parallel manner along the $b$ axis and are supported by a borderline weak $\mathrm{C} 10-\mathrm{H} 10 \cdots \pi$ hydrogen bond $\left[d=3.00 \AA, D=3.806\right.$ (2) $\left.\AA, \theta=144^{\circ}\right]$. The formation of hydrogen-bonded centrosymmetric dimers is the most likely result statistically, as some $95 \%$ of monofunctional carboxylic acids (regardless of the presence or absence of chirality) have been found to do (Allen et al., 1999; Gavezzotti \& Filippini, 1994). In the 2-phenylbutyric acids, it is the optically active forms $R$-PBA and $S$-PBA that are both liquids at room temperature.

A tentative explanation is offered to explain the formation of dimers and catemers in the two closely related (structurally) chiral carboxylic acids. The syn,syn catemer formation in $R$ PPA and $S$-PPA is supported by a $\mathrm{C} 2-\mathrm{H} 2 \cdots \mathrm{O} 2$ hydrogen bond from the chiral carbon centre (See Fig. $5 a$ and Table 2). The $\mathrm{H} 2$ atom is rotated away from the plane of the aromatic ring by $38.7(2)^{\circ}$ in $R$-PPA and $-38.6(3)^{\circ}$ in $S$-PPA, measured from the torsion angle $\mathrm{C} 10-\mathrm{C} 5-\mathrm{C} 2-\mathrm{H} 2 . R S$-PBA acid has a longer hydrocarbon chain which is wider than the aromatic ring. The greater steric size introduced by the butyric chain compared with the propionic chain necessitates a change in motif from catemer to dimer in $R S$-PBA; the latter of which has been shown to be the preferred motif for carboxylic acids with large $R$ groups (Leiserowitz, 1976; Das \& Desiraju, $2006 a, b)$.

\subsection{Crystal structures of co-crystals of chiral carboxylic acids with isonicotinamide}

3.2.1. Co-crystals of 2-phenylpropionic acid and isonicotinamide. The co-crystal (RS-PPA).(INA) formed by liquid

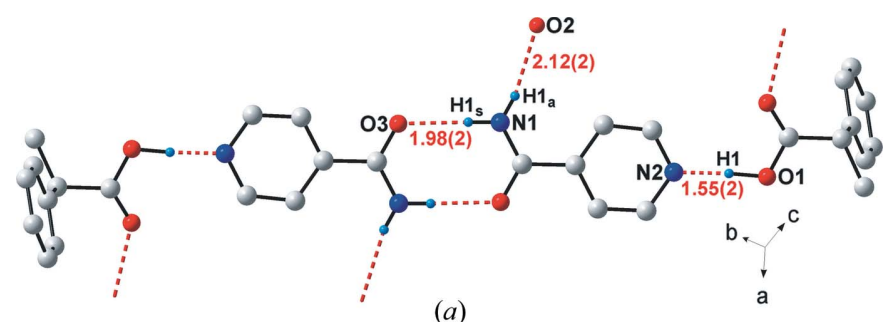

(a)

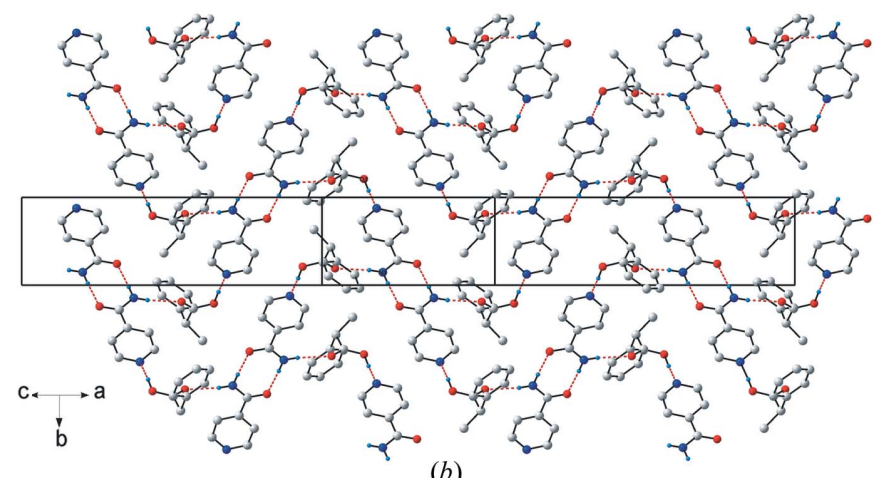

(b)

Figure 6

(a) The supermolecule of (RS-PPA).(INA) and the three unique hydrogen bonds. (b) The two-dimensional network of (RS-PPA).(INA). $\mathrm{H}$ atoms not involved in hydrogen bonding are omitted for clarity. Symmetry codes: (i) $-x+1,-y+2,-z+1$; (ii) $-x+1,-y+1,-z+\frac{3}{2}$. 
( $R S$ )-2-phenylpropionic acid and solid isonicotinamide leads to a supermolecule in the (I) conformation. The asymmetric unit contains one PPA acid molecule and one INA molecule. The PPA acid molecule has a disordered propionic acid chain in such a way as to generate both the $(R)$ and $(S)$ enantiomer simultaneously. The methyl $\mathrm{C} 3 A$ and $\mathrm{C} 3 B$ atoms, both bonded to the chiral carbon centre $(\mathrm{C} 2)$, generate the $(R)$ enantiomer $(\mathrm{C} 1-\mathrm{C} 2-\mathrm{C} 3 A)$ and the $(S)$ enantiomer $(\mathrm{C} 1-\mathrm{C} 2-\mathrm{C} 3 B)$. The ratio of $(R)$ to $(S)$ is 62:38. The other half of the supermolecule is generated by the centre of inversion and generates the correct ratio of enantiomer to complete the racemate ratio of 50:50. The three unique hydrogen bonds contained within each supermolecule are shown in Fig. 6(a). The strongest hydrogen bond [shortest $D \cdots A$ distance of $2.631(2) \AA$ ] is between the carboxylic acid and pyridine [synthon (1)]. This is in accordance with Etter's rule of the best hydrogen-bond acceptor and donor associating with each other (Etter, 1990). Second is the homomeric carboxamide dimer [synthon (2): $D$ $=2.879(2) \AA]$ followed by the amide $\cdots$ carbonyl hydrogen

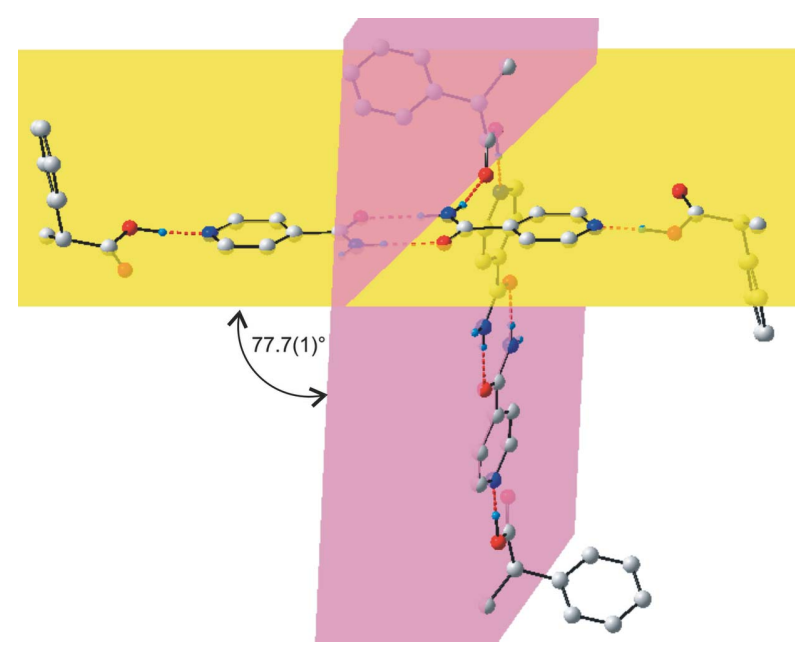

Figure 7

The angle between two adjacent hydrogen-bonded supermolecules in (RS-PPA).(INA), defined by least-squares planes through two adjacent supermolecules.
Table 3

Hydrogen-bonding details for chiral carboxylic acids.

\begin{tabular}{lllll}
\hline$D-\mathrm{H} \cdots A$ & $D-\mathrm{H}(\AA)$ & $\mathrm{H} \cdots A(\AA)$ & $D \cdots A(\AA)$ & $D-\mathrm{H} \cdots A\left({ }^{\circ}\right)$ \\
\hline (I) & & & & \\
$\mathrm{O} 1-\mathrm{H} 1 \cdots \mathrm{O} 2^{\mathrm{i}}$ & $0.93(3)$ & $1.74(3)$ & $2.643(2)$ & $163(2)$ \\
$\mathrm{C} 2-\mathrm{H} 2 \cdots \mathrm{O} 2^{\mathrm{ii}}$ & 1.00 & 2.53 & $3.482(2)$ & 160 \\
& & & & \\
$(\mathrm{II})$ & & & \\
$\mathrm{O} 1-\mathrm{H} 1 \cdots \mathrm{O} 2^{\mathrm{iii}}$ & $0.96(3)$ & $1.74(4)$ & $2.657(3)$ & $159(3)$ \\
$\mathrm{C} 2-\mathrm{H} 2 \cdots \mathrm{O} 2^{\mathrm{iv}}$ & 1.00 & 2.54 & $3.500(3)$ & 160 \\
$(\mathrm{III})$ & & & \\
$\mathrm{O} 1-\mathrm{H} 1 \cdots \mathrm{O} 2^{\mathrm{v}}$ & $0.99(2)$ & $1.67(2)$ & $2.637(1)$ & $172(2)$ \\
\hline
\end{tabular}

Symmetry codes: (i) $\quad-x+1, y-\frac{1}{2},-z$; (ii) $\quad-x+1, y+\frac{1}{2},-z$;

$-x+1, y+\frac{1}{2},-z+2$; (iv) $-x+1, y-\frac{1}{2},-z+2$; (v) $-x+1,-y,-z+1$.

bond [synthon (3): $D=2.964$ (2) $\AA$ ]. Synthon (3) connects adjacent supermolecules which are not co-planar but orientated at $77.8(1)^{\circ}$ (least-squares plane defined by the two INA molecules) relative to each other (Fig. 7). The resulting architecture consists of a cross-linked network of interpenetrating supermolecules as observed by Aakeröy et al. (2002) and shown in Fig. 6(b).

The co-crystal ( $R$-PPA).(INA) formed by solid $(R)$-2phenylpropionic acid and solid isonicotinamide leads to a supermolecule in the (I) conformation. The asymmetric unit contains one complete supermolecule, with an $R$-PPA molecule (molecules $A$ and $B$ ) at both ends and two central INA molecules (molecules $A$ and $B$; Fig. 8). This increases the number of unique hydrogen bonds to six (Table 3). The same trend in hydrogen-bond strength observed in the related racemic version ( $R S$-PPA).(INA) is retained (see Table 3 ) as well as the same architecture. The enantiomorphic co-crystal (S-PPA).(INA) was prepared but no diffraction-quality crystals were available. PXRD confirms that $(S$-PPA).(INA) has the same crystal structure as $(R$-PPA).(INA).

3.2.2. Co-crystals of 2-phenylbutyric acid and isonicotinamide. The co-crystal (RS-PBA).(INA) formed by solid $(R S)$-2-phenylbutyric acid and solid isonicotinamide contains a supermolecule in the (I) conformation. The asymmetric unit contains one $S$-PBA molecule and one INA molecule. The other half of the supermolecule is generated by the centre of inversion and generates the correct ratio of enantiomer to complete the racemate ratio of 50:50. The three unique hydrogen bonds contained within each supermolecule are shown in Fig. 9(a). The strongest hydrogen bond [shortest $D \cdots A$ distance of $2.661(2) \AA]$ is again between the carboxylic acid and pyridine [synthon (1)], followed by synthon (2) $[D=2.902(2) \AA]$ and then synthon (3) $[D=3.051$ (2) $]$. Synthon (3) connects adjacent
Figure 8

The supermolecule of ( $R$-PPA).(INA) and the six unique hydrogen bonds. $\mathrm{H}$ atoms not involved in hydrogen bonding are omitted for clarity. Symmetry codes: (iii) $-x+1,-y+1,-z+2$; (iv) $-x+1, y-1,-z+1$. 

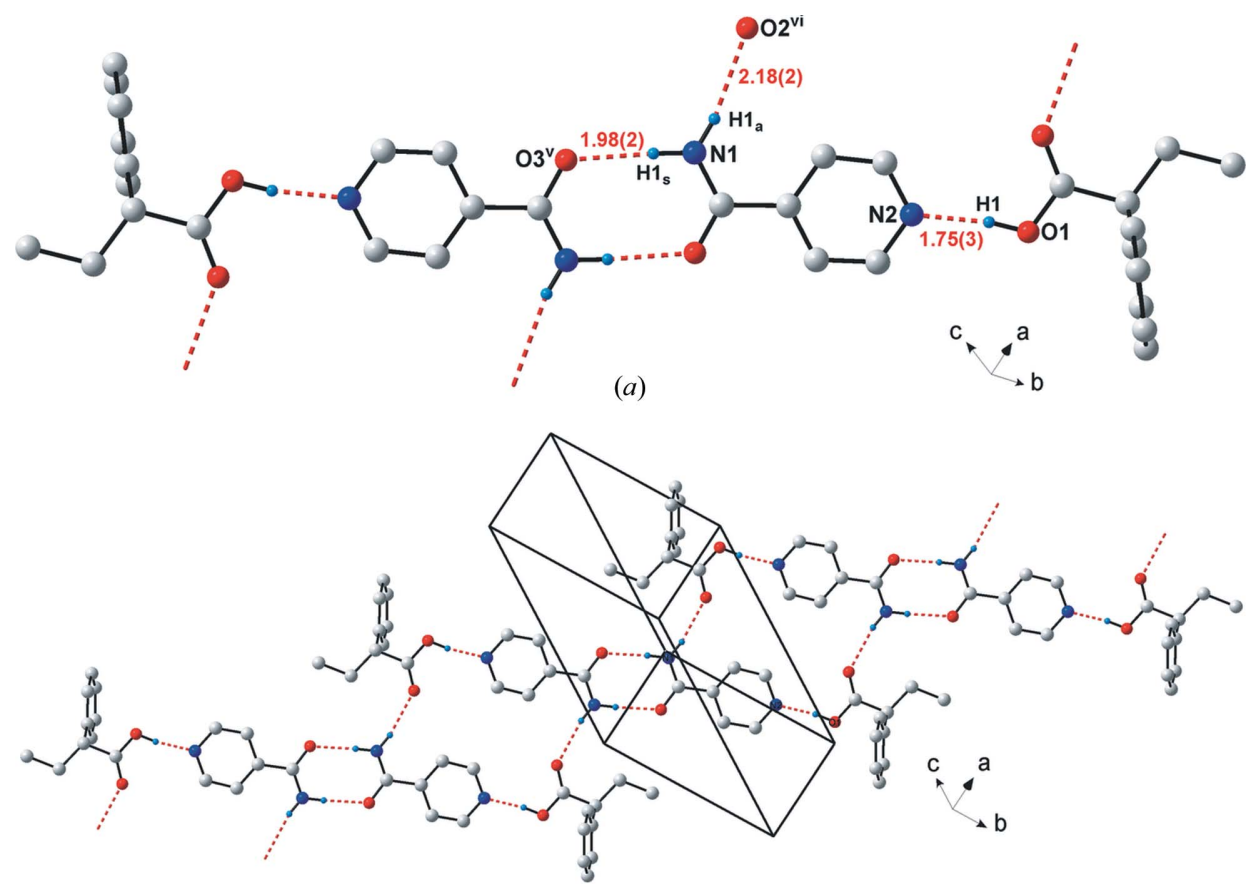

(b)

Figure 9

(a) The supermolecule of (RS-PBA).(INA) and the three unique hydrogen bonds. $(b)$ The onedimensional hydrogen-bonded ribbons. Symmetry codes: (v) $x+2, y+1, z$; (vi) $x-2, y-1, z$. supermolecules that are all coplanar (Fig. 9b). The resulting architecture consists of the onedimensional infinite ribbons described by Aakeröy et al. (2002), extending along the [110] direction. Adjacent ribbons pack in a parallel arrangement (Fig. 10).

As before in the optically active co-crystal ( $R$-PPA).(INA), the cocrystal with a single enantiomer of 2-phenylbutyric acid has a complete supermolecule in the asymmetric unit (Fig. 11). The cocrystal ( $R$-PBA).(INA) formed by liquid $(R)$-2-phenylbutyric acid and solid isonicotinamide has six unique hydrogen bonds (Table 3 ). The same trend in hydrogen-bond strength observed in the related racemic co-crystal $(R S$ PBA).(INA) is retained, as well as the same architecture. The enantiomorphic co-crystal $(S$ PBA).(INA) is structurally identical to $(R$-PBA) $\cdot($ INA).

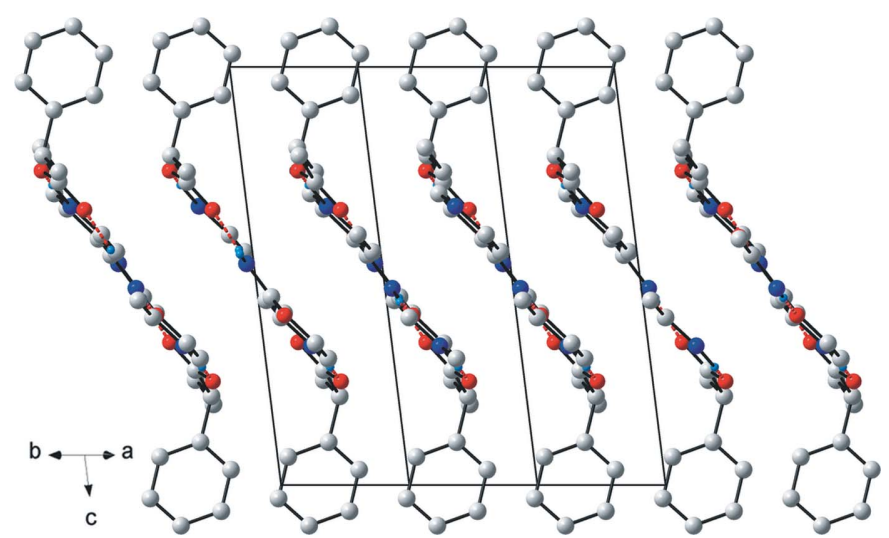

Figure 10

Parallel packing of adjacent ribbons in (RS-PBA).(INA). $\mathrm{H}$ atoms not involved in hydrogen bonding are omitted for clarity.

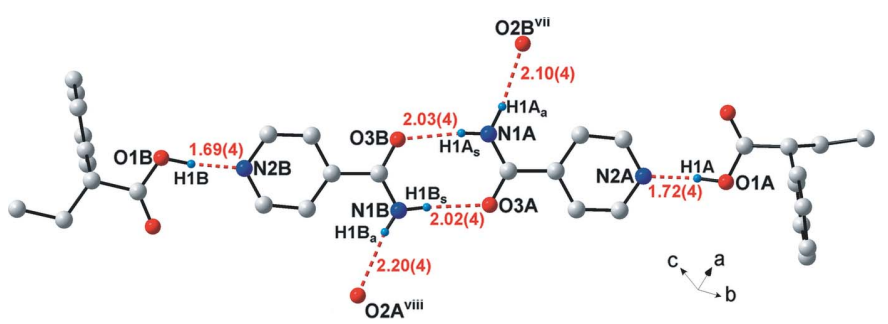

Figure 11

The supermolecule of ( $R$-PBA).(INA) and the six unique hydrogen bonds. $\mathrm{H}$ atoms not involved in hydrogen bonding are omitted for clarity. Symmetry codes: (vii) $x+2, y+1, z$; (viii) $x-2,-y+2,-z+1$.

\section{the effect of chirality on melting-point behaviour}

\subsection{Comparison of structures and}

The packing and geometric quantities of the co-crystals are summarized in Table 4 . The monoclinic $C$-centred space group of the co-crystals with the two-dimensional network ( $C 2$ and $C 2 / c)$ and the triclinic primitive of the ribbon motif ( $P 1$ and $P \overline{1})$ are characteristic for these architectures. The Cambridge Structural Database (CSD, Version 5.27, November 2007 release; Allen, 2002) contains 31 structures of any mono- or dicarboxylic acid and isonicotinamide. ${ }^{4}$ There are seven structures each of the two architectures and all of them crystallize in $C 2 / c$ or $P \overline{1}$. There are no structures reported to date with only a single enantiomer of a chiral acid in a co-crystal with isonicotinamide.

The difference between the racemic and optically active cocrystals is the increase of the asymmetric unit from $Z^{\prime \prime}=2$ to $Z^{\prime \prime}=4$, respectively (van Eijck \& Kroon, 2000). The asymmetric unit of the optically active co-crystals ( $R$-PBA) (INA), $(R$-PBA).(INA) and ( $S$-PBA).(INA) all contain pseudocentrosymmetric supermolecules in which the geometry of the two achiral INA molecules is almost identical, but not that of the single enantiomers of the chiral carboxylic acids. The r.m.s. fit of the overlaid molecules is listed in Table 4, using the method of MolFit with quaternion transformation (Mackay, 1984). However, the most striking difference (and the central feature of this study) is the correlation between chirality (and

${ }^{4}$ Filters: only organics; 37 hits which were reduced by manual inspection by eliminating structures with charged species, solvent molecules, duplicate entries and those with only synthons (1) and (2). 
Table 4

Hydrogen bonding details for co-crystals [except (VI)].

\begin{tabular}{|c|c|c|c|c|}
\hline$D-\mathrm{H} \cdots A$ & $\begin{array}{l}D-\mathrm{H} \\
(\AA)\end{array}$ & $\begin{array}{l}\mathrm{H} \cdots A \\
(\AA)\end{array}$ & $\begin{array}{l}D \cdots A \\
(\AA)\end{array}$ & $\begin{array}{l}<(D-\mathrm{H} \cdots A) \\
\left(^{\circ}\right)\end{array}$ \\
\hline \multicolumn{5}{|l|}{$(R S$-PPA) $($ INA) } \\
\hline $\mathrm{O} 1-\mathrm{H} 1 \cdots \mathrm{N} 2$ & $1.08(2)$ & $1.55(2)$ & $2.631(2)$ & $175(2)$ \\
\hline $\mathrm{N} 1-\mathrm{H} 1_{\mathrm{s}} \cdots \mathrm{O} 3^{\mathrm{i}}$ & $0.90(2)$ & $1.98(2)$ & $2.879(2)$ & $177(2)$ \\
\hline $\mathrm{N} 1-\mathrm{H} 1_{\mathrm{a}} \cdots \mathrm{O} 3^{\mathrm{ii}}$ & $0.86(2)$ & $2.12(2)$ & $2.964(2)$ & $167(2)$ \\
\hline \multicolumn{5}{|l|}{$(R$-PPA $) \cdot($ INA $)$} \\
\hline $\mathrm{O} 1 A-\mathrm{H} 1 A \cdots \mathrm{N} 2 A$ & $0.99(4)$ & $1.65(4)$ & $2.635(4)$ & $173(3)$ \\
\hline $\mathrm{O} 1 B-\mathrm{H} 1 B \cdots \mathrm{N} 2 B$ & $1.04(3)$ & $1.59(4)$ & $2.628(3)$ & $178(3)$ \\
\hline $\mathrm{N} 1 A-\mathrm{H} 1 A_{\mathrm{s}} \cdots \mathrm{O} 3 B$ & $1.09(3)$ & $1.80(3)$ & $2.883(4)$ & $171(3)$ \\
\hline $\mathrm{N} 1 A-\mathrm{H} 1 A_{\mathrm{a}} \cdots \mathrm{O} 2 A^{\mathrm{iii}}$ & $0.88(3)$ & $2.15(3)$ & $3.022(3)$ & $171(3)$ \\
\hline $\mathrm{N} 1 B-\mathrm{H} 1 B_{\mathrm{s}} \cdots \mathrm{O} 3 A$ & $0.86(4)$ & $2.02(4)$ & $2.873(4)$ & $175(3)$ \\
\hline $\mathrm{N} 1 B-\mathrm{H} 1 B_{\mathrm{a}} \cdots \mathrm{O} 2 B^{\mathrm{iv}}$ & $0.96(3)$ & $1.97(3)$ & $2.911(3)$ & $170(3)$ \\
\hline \multicolumn{5}{|l|}{$(R S-\mathrm{PBA}) \cdot(\mathrm{INA})$} \\
\hline $\mathrm{O} 1-\mathrm{H} 1 \cdots \mathrm{N} 2$ & $0.91(2)$ & $1.75(3)$ & $2.661(2)$ & $172(2)$ \\
\hline $\mathrm{N} 1-\mathrm{H} 1_{\mathrm{s}} \cdots \mathrm{O} 3^{\mathrm{v}}$ & $0.93(2)$ & $1.98(2)$ & $2.902(2)$ & $177(2)$ \\
\hline $\mathrm{N} 1-\mathrm{H} 1_{\mathrm{a}} \cdots \mathrm{O} 3^{\mathrm{vi}}$ & $0.89(2)$ & $2.18(2)$ & $3.051(2)$ & $169(2)$ \\
\hline \multicolumn{5}{|l|}{$(R$-PBA $) \cdot($ INA $)$} \\
\hline $\mathrm{O} 1 A-\mathrm{H} 1 A \cdots \mathrm{N} 2 A$ & $0.95(4)$ & $1.72(4)$ & $2.653(4)$ & $165(4)$ \\
\hline $\mathrm{O} 1 B-\mathrm{H} 1 B \cdots \mathrm{N} 2 B$ & $0.97(4)$ & $1.69(4)$ & $2.661(4)$ & $172(3)$ \\
\hline $\mathrm{N} 1 A-\mathrm{H} 1 A_{\mathrm{s}} \cdots \mathrm{O} 3 B$ & $0.87(4)$ & $2.03(4)$ & $2.893(4)$ & $169(3)$ \\
\hline $\mathrm{N} 1 A-\mathrm{H} 1 A_{\mathrm{a}} \cdots \mathrm{O} 2 A^{\mathrm{vii}}$ & $0.97(4)$ & $2.10(4)$ & $3.065(4)$ & $171(3)$ \\
\hline $\mathrm{N} 1 B-\mathrm{H} 1 B_{\mathrm{s}} \cdots \mathrm{O} 3 A$ & $0.89(4)$ & $2.02(4)$ & $2.905(4)$ & $170(3)$ \\
\hline $\mathrm{N} 1 B-\mathrm{H} 1 B_{\mathrm{a}} \cdots \mathrm{O} 2 B^{\text {viii }}$ & $0.82(4)$ & $2.20(4)$ & $3.003(4)$ & $170(4)$ \\
\hline \multicolumn{5}{|l|}{$(S$-PBA $) \cdot($ INA $)$} \\
\hline $\mathrm{O} 1 A-\mathrm{H} 1 A \cdots \mathrm{N} 2 A$ & $0.88(5)$ & $1.78(5)$ & $2.652(3)$ & $173(4)$ \\
\hline $\mathrm{O} 1 B-\mathrm{H} 1 B \cdots \mathrm{N} 2 B$ & $0.83(4)$ & $1.93(4)$ & $2.662(3)$ & $147(4)$ \\
\hline $\mathrm{N} 1 A-\mathrm{H} 1 A_{\mathrm{s}} \cdots \mathrm{O} 3 B$ & $0.77(4)$ & $2.13(5)$ & $2.897(3)$ & $171(4)$ \\
\hline $\mathrm{N} 1 A-\mathrm{H} 1 A_{\mathrm{a}} \cdots \mathrm{O} 2 A^{\mathrm{viii}}$ & $1.00(4)$ & $2.08(4)$ & $3.062(3)$ & $169(3)$ \\
\hline $\mathrm{N} 1 B-\mathrm{H} 1 B_{\mathrm{s}} \cdots \mathrm{O} 3 A$ & $0.90(5)$ & $2.04(5)$ & $2.901(3)$ & $160(4)$ \\
\hline $\mathrm{N} 1 B-\mathrm{H} 1 B_{\mathrm{a}} \cdots \mathrm{O} 2 B^{\mathrm{vii}}$ & $0.82(4)$ & $2.19(5)$ & $3.002(4)$ & $170(4)$ \\
\hline
\end{tabular}

Symmetry codes: (i) $-x+1,-y+2,-z+1$; (ii) $-x+1,-y+1,-z+\frac{3}{2}$; (iii) $-x+1, y+1,-z+2$; (iv) $-x+1, y-1,-z+1$; (v) $-x,-y+1,-z+1$; (vi) $-x+2,-y+2,-z+1$; (vii) $x+2, y+1, z$; (viii) $x-2, y-1, z$.

the resulting absence of favourable packing symmetry elements) and the observed melting point (see supplementary material for DSC traces). Even though the three structures of the co-crystals of PBA and INA occur between chemically identical species and have identical types of intermolecular interactions and distances (see Table 4), the racemic co-crystal $(R S$-PBA) (INA) melts some $16 \mathrm{~K}$ higher than the two optically active co-crystals ( $R$-PBA).(INA) and ( $S$-PBA) (INA). Less extreme are the melting points of co-crystals of PPA acid and INA, where the difference is only $4 \mathrm{~K}$ higher between the racemate (RS-PPA).(INA) and optically active $(R$ PPA) (INA) and ( $S$-PPA) (INA). The differing extent of the melting point differential between these two systems is almost certainly due to the properties of the chiral carboxylic acids themselves. The racemic chiral carboxylic acid used in the PBA co-crystals has a higher melting point than its optically active form, thus having an additive effect on the resulting cocrystal melting points, as seen in (ibuprofen).(nicotinamide) (Friščić \& Jones, 2007). When PPA is the chiral carboxylic acid, where the racemate has a lower melting point than its optically active form, the resulting co-crystals do not follow this trend and counteract it to a small degree. However, even though the crystal packing architecture is different in the four optically active co-crystals studied, their melting points are all within $2 \mathrm{~K}$ of each other. The calculated crystal density (Table 1) and the packing efficiency (Table 4) all follow the same trend of being denser and better packed in the racemic cocrystals over the optically active co-crystals. Both inversion and correlation of the melting points of a series of $n$-alkyl carboxylic acids with those of the melting points of their cocrystalline complexes has been observed using pyrazine (Bond, 2006) and isonicotinamide (Vishweshar et al., 2003), respectively.

Geometrically, the co-crystals have similar features. The conformational freedom of the INA molecules and the chiral PPA and PBA molecules is restricted to rotation around the single bond connecting the pyridine ring and the carboxamide group, and the benzene ring and the hydrocarbon carboxylic acid chain, respectively. The INA molecules are generally flat in (RS-PPA).(INA) and (R-PPA) (INA) (C12-C11-C16$\mathrm{N} 1$ torsion angles are syn-periplanar), and the propionic acid chain perpendicular to the aromatic ring $(\mathrm{C} 10-\mathrm{C} 5-\mathrm{C} 2-\mathrm{C} 1$ torsion angles are synclinal). This geometry continues to the racemic co-crystal ( $R S$-PBA) . (INA). However, the individual molecules in the optically active co-crystals ( $R$-PBA).(INA) and $(S$-PBA) . (INA) have different torsion angles for the INA, reflected in their higher r.m.s. ( $R$-PBA).(INA): $0.079 \AA$, $(S$ PBA).(INA): $0.025 \AA$, fit for those molecules compared with $(R$-PPA $) \cdot($ INA $) \quad(0.025 \AA)$. The two unique $R$-PBA molecules in ( $R$-PBA) (INA) have different relative conformations of the butyryl acid chain, being - anticlinal ($\left.104.3(4)^{\circ}\right)$ and + synclinal $\left[74.6(3)^{\circ}\right]$. The same happens in $(S$ PBA).(INA) (see Table 4).

\section{Conclusion}

In this report, we have investigated the single-crystal structures of two sets of co-crystals between chiral carboxylic acids, 2-phenylpropionic and 2-phenylbutyric acid, and isonicotinamide. As part of the study, the single-crystal structures of the chiral carboxylic acids that are solids at room temperature were determined. (R)-2-Phenylpropionic acid and $(S)$-2phenylpropionic acid form catemers and melt at 302-303 K. $(R S)$-2-Phenylpropionic acid is a liquid at room temperature. $(R S)$-2-Phenylbutyric acid, melting at 313-315 K, rather forms the dimer motif in the solid state, possibly because of the greater steric size of the butyric chain compared with the propionic chain. Thus, $(R S)$-2-phenylbutyric acid packs in the general preferred motif for carboxylic acids and this series has melting-point behaviour in accordance with Wallach's rule, as $(R)$-2-phenylbutyric and $(S)$-2-phenylbutyric acid are liquids at room temperature. However, the 2-phenylpropionic acid series has the opposite melting point behaviour and hence is an exception to the rule. Thus, when it comes to singlecomponent chiral crystals, the authors feel that no conclusions can be made with regard to the relative stability of the racemate over the optically active form. Further understanding of the differing behaviour of these two sets of chiral carboxylic acids may come from the crystal structures of the carboxylic 
Table 5

Summary of comparative structural features in co-crystals.

\begin{tabular}{|c|c|c|c|c|c|c|}
\hline & $(R S$-PPA $) \cdot($ INA $)$ & $(R$-PPA $) \cdot(\mathrm{INA})$ & $(S$-PPA $) \cdot($ INA $) \dagger$ & $(R S$-PBA $) \cdot($ INA $)$ & $(R$-PBA $) \cdot(\mathrm{INA})$ & $(S$-PBA $) \cdot($ INA $)$ \\
\hline Space group & $C 2 / c$ & $C 2$ & $C 2$ & $P \overline{1}$ & $P 1$ & $P 1$ \\
\hline Melting point $(\mathrm{K})$ & 364 & 360 & 359 & 377 & 361 & 361 \\
\hline K.P.I. $\ddagger$ & 68.1 & 67.3 & - & 70.7 & 69.8 & 70.0 \\
\hline $\begin{array}{l}\text { Crystal packing } \\
\text { architecture }\end{array}$ & $\begin{array}{l}\text { Cross-linked two- } \\
\text { dimensional } \\
\text { network }\end{array}$ & $\begin{array}{l}\text { Cross-linked two- } \\
\text { dimensional } \\
\text { network }\end{array}$ & $\begin{array}{l}\text { Cross-linked two- } \\
\text { dimensional } \\
\text { network }\end{array}$ & $\begin{array}{l}\text { One-dimensional } \\
\text { ribbon }\end{array}$ & $\begin{array}{l}\text { One-dimensional } \\
\text { ribbon }\end{array}$ & $\begin{array}{l}\text { One-dimensional } \\
\text { ribbon }\end{array}$ \\
\hline $\begin{array}{l}\text { Synthon (1) } D \cdots A \\
(\AA)\end{array}$ & $2.631(2)$ & $2.632(5)$ & - & $2.661(2)$ & $2.657(6)$ & $2.657(7)$ \\
\hline $\begin{array}{l}\text { Synthon (3) } D \cdots A \\
\text { (§) }\end{array}$ & $2.964(2)$ & $2.967(78)$ & - & $3.051(2)$ & $3.034(44)$ & $3.032(42)$ \\
\hline $\begin{array}{l}\text { Angle between } \\
\text { supermolecules }\left({ }^{\circ}\right)\end{array}$ & $77.8(1)$ & $76.7(1)$ & - & 0 & 0 & 0 \\
\hline $\begin{array}{r}\text { Conformation of } \\
\text { supermolecule }\end{array}$ & $\mathrm{I}(t-t-t)$ & I $(t-t-t)$ & I $(t-t-t)$ & I $(t-t-t)$ & I $(t-t-t)$ & I $(t-t-t)$ \\
\hline$\pi \cdots \pi(\AA)$ & $5.234(1)$ & $5.185(1)$ & - & $3.713(1)$ & $3.811(2)$ & $3.793(2)$ \\
\hline $\begin{array}{l}\mathrm{C} 12-\mathrm{C} 11-\mathrm{C} 16-\mathrm{N} 1 \\
\left({ }^{\circ}\right)\end{array}$ & $-3.5(3)$ & $-4.1(5) A$ & - & $11.1(2)$ & 3.4 (4) $A$ & -4.2 (4) $A$ \\
\hline \multirow[t]{2}{*}{$\begin{array}{l}\mathrm{C} 10-\mathrm{C} 5-\mathrm{C} 2-\mathrm{C} 1 \\
\left({ }^{\circ}\right)\end{array}$} & $70.9(2)$ & $\begin{array}{l}2.8(5) B \\
73.1(4) A\end{array}$ & - & $-76.2(2)$ & $\begin{array}{l}-12.8(5) B \\
-104.2(3) A\end{array}$ & $\begin{array}{l}13.7 \text { (4) } B \\
106.1(3) A\end{array}$ \\
\hline & & $-72.1(3) B$ & & & 74.6 (3) $B$ & $-75.1(3) B$ \\
\hline
\end{tabular}

$\dagger$ Entries not determined from SCXRD but assumed to be identical to (R-PPA).(INA). $\quad$ PLATON (Spek, 2003).

acids that are liquids at room temperature, which is the subject of further study.

The co-crystals with 2-phenylpropionic acid and isonicotinamide form two-dimensional cross-linked networks, whereas the co-crystals with 2-phenylbutyric acid and isonicotinamide form one-dimensional ribbons. All of the co-crystals studied form similar supermolecules in the (I) conformation. However, there is an increase of the asymmetric unit from $Z^{\prime \prime}$ $=2$ to $Z^{\prime \prime}=4$ for the chiral co-crystals $(R)$-2-phenylpropionic acid-isonicotinamide $(360 \mathrm{~K}), \quad(R)$-2-phenylbutyric acid-isonicotinamide $(361 \mathrm{~K})$ and $(S)$-2-phenylbutyric acid-isonicotinamide $(361 \mathrm{~K})$, and subtle differences in their molecular geometries. In turn, the melting points of these chiral co-crystals is lower than those of their corresponding racemic co-crystals $(R S)$-2-phenylpropionic acid-isonicotinamide $(364 \mathrm{~K})$ and $(R S)$-2-phenylbutyric acid-isonicotinamide $(377 \mathrm{~K})$. Packing efficiencies and crystal densities indicate that the racemic structures pack more closely and hence are likely to be more thermally stable. Seeing that the crystal packing architecture within each set of chiral carboxylic acids is identical regardless of the identity of the carboxylic acid, the results support Brock's argument, quoted in the introduction, of the more favourable symmetry elements inherent in racemic space groups $(P \overline{1}$ and $C 2 / c)$ compared with their optically active counterparts $(P 1$ and $C 2$, respectively) as the reason for the different solid-state behaviour. Nonetheless, it is too early to tell whether this property is applicable to all chiral co-crystals until more data points have been gathered.

Financial support was received from the South African National Research Foundation (NRF) (Grant FA2006030100003). AL thanks the NRF for a postdoctoral scholarship (SFP2006061500015) and NBB thanks the NRF for a postdoctoral fellowship (SPF2005072700016).

\section{References}

Aakeröy, C. B., Beatty, A. M. \& Helfrich, B. A. (2002). J. Am. Chem. Soc. 124, 14425-14432.

Aakeröy, C. B. \& Salmon, D. J. (2005). CrystEngComm, 7, 439-448. Allen, F. H. (2002). Acta Cryst. B58, 380-388.

Allen, F. H., Motherwell, W. D. S., Raithby, P. R., Shields, G. P. \& Taylor, R. (1999). New J. Chem. 23, 25-34.

Bond, A. D. (2006). CrystEngComm, 8, 333-337.

Bond, A. D. (2007). CrystEngComm, 9, 833-834.

Brandenburg, K. (1999). DIAMOND, Version 2.1e. Crystal Impact GbR, Bonn, Germany.

Brock, C. P., Schweizer, W. B. \& Dunitz, J. D. (1991). J. Am. Chem. Soc. 113, 9811-9820.

Bruker AXS Inc. (2004). SAINT-PLUS, Version 7.12. Bruker AXS Inc., Madison, Wisconsin, USA.

Childs, S. L. \& Hardcastle, K. I. (2007). Cryst. Growth Des. 7, 12911304.

Das, D. \& Desiraju, G. R. (2006a). Chem. Asian J. 1-2, 231-244.

Das, D. \& Desiraju, G. R. (2006b). CrystEngComm, 8, 674-679.

Desiraju, G. R. (2005). Chem. Commun. pp. 2995-3001. 
Eijck, B. P. van \& Kroon, J. (2000). Acta Cryst. B56, 535-542.

Etter, M. C. (1990). Acc. Chem. Res. 13, 120-126.

Farrugia, L. J. (1997). J. Appl. Cryst. 30, 565.

Farrugia, L. J. (1999). J. Appl. Cryst. 32, 837-838.

Friščić, T., Fábián, L., Burley, J. C., Reid, D. G., Duer, M. J. \& Jones, W. (2008). Chem. Commun. pp. 1644-1646.

Friščić, T. \& Jones, W. (2007). Faraday Discuss. 136, 167-178.

Gabard, J. \& Collett, A. (1986). Nouveau J. Chim. 10, 685-690.

Gavezzotti, A. \& Filippini, G. (1994). J. Phys. Chem. 98, 4831-4837.

Larsen, S. \& Marthi, K. (1994). Acta Cryst. B50, 373-381.

Larsen, S. \& Marthi, K. (1995). Acta Cryst. B51, 338-346.

Larsen, S. \& Marthi, K. (1997). Acta Cryst. B53, 280-292.

Leiserowitz, L. (1976). Acta Cryst. B32, 775-802.

Mackay, A. L. (1984). Acta Cryst. A40, 165-166.

Marthi, K., Larsen, S., Ács, M., Bálint, J. \& Fogassy, E. (1994). Acta Cryst. B50, 762-771.
Moulton, B. \& Zaworotko, M. J. (2001). Chem. Rev. 101, 1629-1658. Nonius (1998). COLLECT. Nonius BV, Delft, The Netherlands. Otwinowski, Z. \& Minor, W. (1997). Methods in Enzymology, Vol. 276, Macromolecular Crystallography, edited by C. W. Carter Jr \& R. M. Sweet, Part A, pp. 307-326. New York: Academic Press.

Remenar, J. F., Morisette, S. L., Peterson, M. L., Moulton, B., MacPhee, J. M., Guzmán, H. R. \& Almarsson, Ö. (2003). J. Am. Chem. Soc. 125, 8456-8457.

Riis, E. \& Larsen, S. (2005). Acta Cryst. E61, o1396-o1397.

Sheldrick, G. M. (2008). Acta Cryst. A64, 112-122.

Sørensen, H. O. \& Larsen, S. (2003). Acta Cryst. B59, 132-140.

Spek, A. L. (2003). J. Appl. Cryst. 36, 7-13.

Vishweshar, P., McMahon, J. A., Bis, J. A. \& Zaworotko, M. J. (2006). J. Pharm. Sci. 95, 499-516.

Vishweshar, P., Nangia, A. \& Lynch, V. M. (2003). Cryst. Growth Des. 3, 783-790. 